\title{
Research on the hydromineral metabolism in rabbits suffering from diarrhoea
}

\author{
D. LICOIS et P. COEDER'T \\ Station de pathologie aviaive, \\ Centre de Recherches de Touts, I.N.R.A., Nouzilly, 37380 Monnaie (lirance)
}

\begin{abstract}
"Diarrhoea $n$ in rabbits, induced by experimental infestation witl various coccidae does absolutely not resemble the "classical " diarrhoea encountered in young mammals such as calves and infants.

Hydrous and mineral losses througl the faeces were lower than in healthy animals. As the hematocrite and proteinemia decreased and as the diuresis was almost normal, this phenomenon can be considered as a haemodilution. The concentration of all plasma electrolytes studied decreased and the blood $\mathrm{pH}$ remained normal. In the intestine, the absence of a "true " diarrhoea can be explained by a very good re-absorption of water in the distal colon. The sodium seemed to be "badly absorbed " in the small intestine. As regards the potassium, and as compared to the controls, changes occurred in the caecum. Let us mention that despite the low feed intake, the apparent digestibility of minerals was highly reduced. With respect to the water metabolism, no dehydration was observed in the extracellular region: only the skin was largely dehydrated.
\end{abstract}

\section{Rabbit coccidae and their pathogenicity}

\author{
P. COUDERT \\ Station de pathologie aviaire, \\ Centre de Recherches de Tours, I.N.R.A., Nouzilly, 37380 Monnaie (France)
}

Rabbit coccidae were isolated as pure strains in SPF rabbits. The pathogenicity of six of these coccidae was estimated and compared with respect to growth and mortality in the experimentally infested animals. According to the results obtained, the coccidae can be ranked into 3 categories :

I) Very pathogenic coccidae: Emeria intestinalis and $E$. pellerdyi, mortality occurs with infestations of 5000 oocysts, 50000 oocysts cause 100 p. 100 mortality; diarrhoea is serere and the delay of growth very large.

2) A pathogenic coccidium : $:$. magna, leading to very few mortality cases eren with severe infestations (500 000 oocystes), but important diarrhoea and growth delay.

3) Little or non pathogenic coccidae : E. perforans, E. exigua and E. ncoleporis, causing neither death nor diarrhoea and an almost neglectable delay in growth. 